\title{
Zinc-Based Fixative
}

National Cancer Institute

\section{Source}

National Cancer Institute. Zinc-Based Fixative. NCI Thesaurus. Code C84519.

A fixative solution which contains zinc salts. 